\title{
Enucleação em serpente urutu (Bothrops alternatus) no tratamento de endoftalmite decorrente de traumatismo de escama corneal
}

\author{
Urutu (Bothrops alternatus) snake enucleation in the \\ treatment of endophthalmitis resulting from spectacle trauma
}

\section{Kelly Cristine de Sousa Pontes ${ }^{{ }^{*}}$ Moacir Carreta Júnior ${ }^{\mathrm{I}}$ Luis Eugênio Franklin Augusto ${ }^{\mathrm{I}}$}

\section{- NOTA -}

\section{RESUMO}

A urutu, Bothrops alternatus, é uma espécie de serpente peçonhenta da família Viperidae e subfamília Crotalinae. Como em outras espécies, ela pode ser acometida por acidentes ofídicos em algumas situações. Relata-se o caso de uma urutu que teve a escama corneal traumatizada em decorrência do ataque de outra cobra do mesmo gênero há 30 dias. Ao exame oftálmico, notou-se a presença de crosta recobrindo exsudato caseoso localizado no espaço subespetacular. Durante a exploração cirúrgica, foi removida a escama corneal e o exsudato caseoso, notando-se o quadro de endoftalmite. Procedeu-se à enucleação do bulbo acometido e o animal se recuperou bem. Diante de alguns casos, especificamente os que envolvem animais peçonhentos, o tratamento clínico com sua manipulação várias vezes ao dia tornase inviável, sendo recomendado um tratamento cirúrgico definitivo.

Palavras-chave: cobra, oftalmologia, uveíte, enucleação.

\section{ABSTRACT}

The urutu (Bothrops alternatus) belongs to the Viperidae family and to the subfamily of venomous vipers, the Crotalinae. As with all other species the urutu is also susceptible to ophidian accidents. This is a case report of an urutu snake brought to the veterinary hospital with an injured spectacle. According to the clinical history, this lesion was caused by the attack of another snake of the same genus about 30 days earlier. Ophthalmic examination revealed a crust overlaying cheesy exudates just in the subspectacle space. After removal of these from the eye, an endophthalmitis was discovered. Enucleation of the affected ocular globe was performed allowing full recovery of the animal. Poisonous animals are difficult to handle, and I are important limitation to managements that require prolonged and multiple treatments throughout the day. Hence, in such cases, the preference for radical surgical procedures might be justifiable.

Key words: snake, ophthalmology, uveitis, enucleation.
As cobras não possuem pálpebras móveis. Ao invés disso, elas possuem pálpebras transparentes e fundidas que recebem o nome de escama corneal (GIRLING, 2003), por isso elas também não apresentam reflexo palpebral (CULLEN et al., 2000). A escama corneal está separada da córnea pelo espaço subespetacular, alinhada ao longo do epitélio corneal, e é removida juntamente com a pele na fase em que ocorre a ecdise normal das cobras (KERN, 2007).

A uveíte consiste na inflamação da úvea, que é composta pela íris, corpo ciliar e coroide. A endoftalmite é uma condição mais grave, neste caso, a inflamação envolve as cavidades oculares e os componentes anatômicos adjacentes. A panoftalmite é a inflamação envolvendo todas as túnicas oculares, podendo resultar em sinais de doenças orbitárias (HENDRIX, 2007).

O objetivo deste trabalho foi relatar um caso de enucleação do bulbo ocular de uma serpente urutu (Bothrops alternatus), decorrente de trauma de escama corneal não tratada, evidenciando-se tanto a técnica anestésica quanto a cirúrgica utilizada.

Uma urutu (Bothrops alternatus) proveniente do Museu de Zoologia da Universidade Federal de Viçosa foi encaminhada para o Hospital Veterinário da FAVIÇOSA/ UNIVIÇOSA, com histórico de que há aproximadamente 30 dias havia sido colocada em um mesmo recinto com outra cobra do mesmo gênero, havendo uma briga entre elas. Durante o ataque, a serpente teve seu olho direito

'Departamento de Medicina Veterinária, Faculdade de Ciências e Tecnologia de Viçosa (FAVIÇOSA), União de Ensino Superior de Viçosa (UNIVIÇOSA), Rua Olinda Martins Dantonino, 131/101, 36570-000, Bairro Liberdade, Viçosa, MG, Brasil. E-mail: kellycpontes@yahoo.com.br. *Autor para correspondência. 
ferido e, desde então, apresentou hiporexia e apatia. O animal foi submetido à avaliação oftálmica, tendo sido notada a presença de crosta recobrindo exsudato caseoso que se situava no espaço subespetacular (Figura 1C). Prescreveu-se tratamento com enrofloxacino (5mg kg-1) por via intramuscular (IM) em dose única por um dia (CARPENTER, et al. 2001). Foi recomendada a remoção da escama corneal e do exsudato caseoso para exploração do olho acometido com a paciente sob anestesia geral.

O protocolo anestésico instituído foi medicação pré-anestésica com associação de

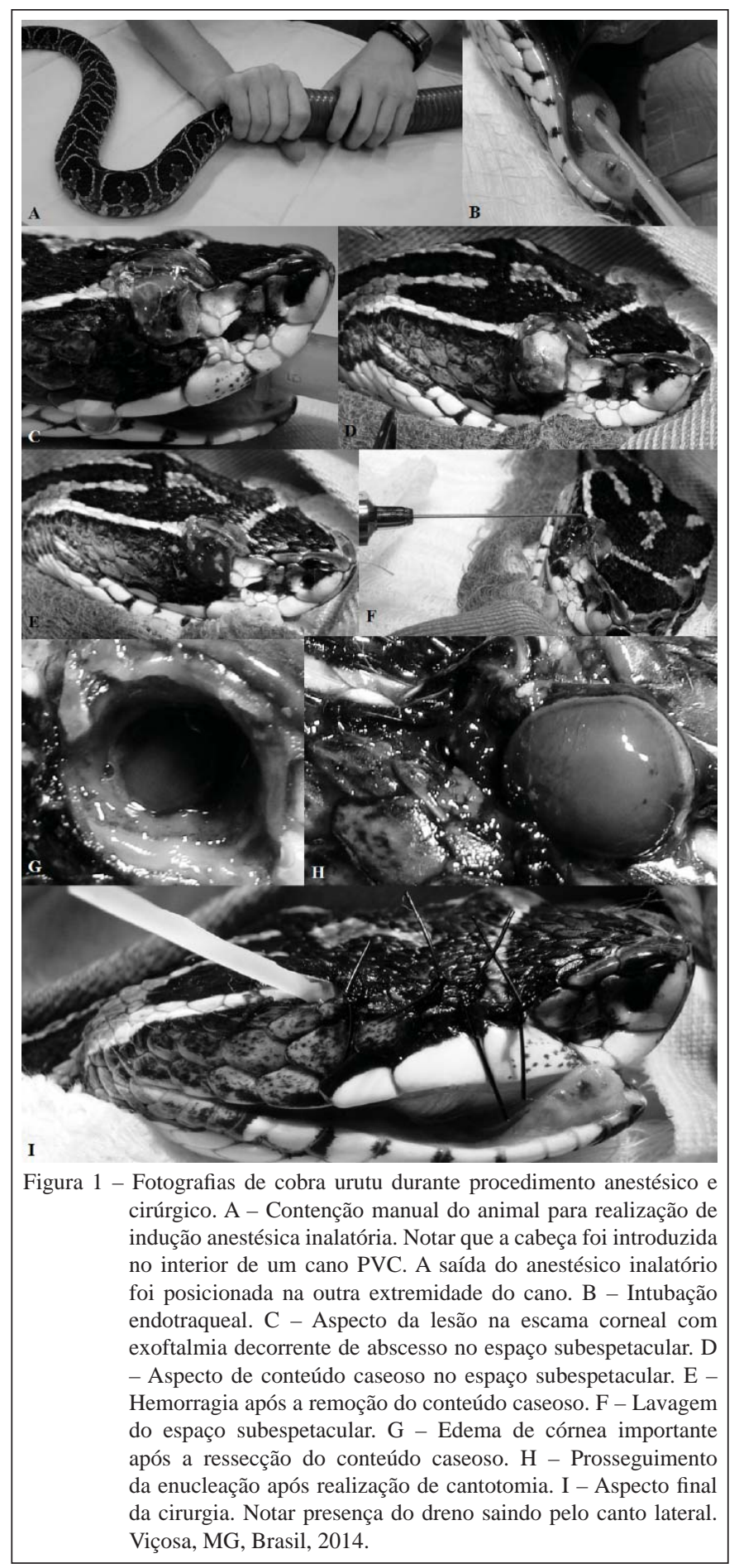

Ciência Rural, v.44, n.6, jun, 2014. 
cetamina (7,5mg kg-1), midazolam (1mg kg-1) e morfina $\left(0,4 \mathrm{mg} \mathrm{kg}^{-1}\right)$, administrados na musculatura paravertebral da metade caudal do corpo. Para restringir sua movimentação e diminuir os riscos de acidentes, além de permitir a realização do exame físico inicial e a administração IM da medicação, o animal foi contido em um tubo de plástico do tipo PVC (Figura 1A). A anestesia foi iniciada com isofluorano diluído em 100\% de oxigênio, conectando-se a saída de gases do aparelho de anestesia à extremidade oposta do tubo em que o animal se encontrava contido. Após cinco minutos, com o auxílio de um espéculo vaginal pequeno, o animal foi intubado, utilizando-se, como sonda endotraqueal, um cateter intravenoso número 14G, sem o mandril, ligado a um conector de sonda endotraqueal número três (Figura 1B). Durante a anestesia, foram monitoradas a frequência cardíaca (FC), com auxílio do doppler ultrassônico vascular, posicionado na região do coração, e a frequência respiratória (FR), através da movimentação do balão respiratório. A taxa de $6 \mathrm{mpm}$ foi mantida por ventilação controlada durante o período transoperatório e por três horas do pós-operatório. Após a recuperação, o animal foi transferido para uma sala aquecida.

Procedeu-se à antissepsia da região periocular direita com solução de iodopovidona $10 \%$ e aplicação de panos de campo. Sob constante irrigação com solução salina isotônica estéril, foi realizada a remoção cirúrgica da escama corneal que apresentava ressecamento e adesão às pálpebras. Sob a escama corneal, notou-se a presença de grande quantidade de exsudato caseoso, o qual foi removido, e procedeu-se à lavagem da superfície ocular com solução de iodopovidona 0,5\% (Figuras 1D). Durante a remoção do conteúdo caseoso, houve sangramento (Figura 1E) e, após a limpeza da região (Figura $1 \mathrm{~F}$ ), pôde-se observar a superfície da córnea que apresentava edema, porém permitindo a vizibilização da íris com rubeosis iridis. Notou-se, ainda, presença de exsudato fibrino hemorrágico na câmara anterior, tendo sido atribuído o diagnóstico de endoftalmite (Figura 1G).

Diante do quadro oftálmico, optou-se pela realização de enucleação do bulbo acometido. Para tanto, foi realizada a cantotomia (Figura $1 \mathrm{H}$ ) com auxílio de lâmina de bisturi número 15, montada em cabo número três. Procedeu-se à dissecção romba dos tecidos perioculares com a secção dos músculos extrínsecos do bulbo ocular. Em seguida, foi aplicada uma pinça hemostática de Halsted curva nos vasos e nervo óptico, seguindo-se a realização de ligadura em massa, utilizando-se fio de náilon monofilamentar
2-0. Após a ligadura, os vasos e o nervo óptico foram seccionados e a pinça hemostática foi removida. Todo o tecido necrosado foi removido, além das margens palpebrais e de algum tecido conjuntivo. Um fragmento de luva estéril foi cortado para ser aplicado no fundo da ferida cirúrgica, dentro da órbita, para funcionar como dreno. Ele foi fixado aos tecidos mais profundos da órbita com fio de náilon monofilamentar 4-0, utilizando-se sutura em padrão simples interrompido. A pele foi aproximada e suturada com o fio de náilon monofilamentar 4-0 e padrão de sutura simples interrompido (Figura 1I). O tratamento pósoperatório constou de enrofloxacino $\left(5 \mathrm{mg} \mathrm{kg}{ }^{-1}\right)$ por via intramuscular, uma vez ao dia, durante sete dias, e meloxican $\left(0,2 \mathrm{mg} \mathrm{kg}^{-1}\right)$ por via intramuscular, uma vez ao dia, por três dias (CARPENTER et al., 2001).

O motivo pelo qual houve a necessidade de ventilação assistida, durante e por até três horas após o término da cirurgia, foi que a serpente apresentou apneia desde os primeiros minutos após a intubação e permaneceu neste estado até o tempo descrito. A transferência do animal para sala aquecida facilitou a sua recuperação e minimizou o risco de hipotermia, pois, de acordo com HEARD \& STETTER (2013), os répteis reduzem o controle termorregulatório ao longo do período anestésico.

O espaço subespetacular é um local comumente acometido por infecções ou abscedações que podem resultar de perfurações traumáticas de escamas oculares. Inicialmente, o tratamento efetivo para as infecções ou abcessos é a abertura ventral da escama corneal, com coleta de material para realização de cultura e antibiograma, adicionandose lavagem no espaço subespetacular com soluções antibióticas. Os casos que não recebem tratamento podem ser resolvidos espontaneamente ou podem progredir para endoftalmite e panoftalmite. Nestes dois últimos casos, o prognóstico é ruim e o tratamento recomendado pode ser a enucleação do bulbo acometido (KERN, 2007).

A urutu do caso descrito sofreu lesão traumática da escama corneal que não recebeu tratamento e que não foi resolvida espontaneamente. Ao invés disso, o quadro evoluiu para comprometimento do bulbo ocular caracterizado por endoftalmite. Diante do exposto, pensou-se no mesmo tratamento que o instituído para a uveíte, que consiste na administração tópica (quando possível) e sistêmica de antibióticos, além de anti-inflamatório esteroidal e não esteroidal (MILLICHAMP, 2001). Entretanto, a presença da escama corneal poderia impedir a utilização de tratamento tópico para a uveíte, pois esta estrutura é impermeável a medicamentos (CULLEN 
et al., 2000). Neste caso, optou-se pela enucleação do bulbo acometido, porque, mesmo tendo-se removido a escama corneal para a penetração da medicação tópica, por se tratar de animal peçonhento, a administração da medicação tópica em intervalos regulares seria dificultada e arriscada aos tratadores.

Apesar de existirem controvérsias entre alguns pesquisadores, a maioria dos trabalhos em herpetologia conclui ou assume que serpentes são imunes aos efeitos do seu próprio veneno ou a venenos similares, como o de animais do mesmo gênero. Entretanto, os autores citam que elas estão vulneráveis às possíveis consequências das lesões causadas nestes acidentes, incluindo infecções decorrentes dos traumatismos e do contato com a microbiota oral do agressor (WORRELL, 1970; HOSER, 1985). Tais observações explicam o porquê da sobrevivência da urutu do presente relato, mesmo após ela ter sido atacada por outro animal peçonhento e, ainda, esclarece que a endoftalmite ocorreu devido ao trauma na escama corneal, com consequente infecção.

Após cinco dias, foi removido o dreno e, após 10 dias, realizada a remoção da sutura da pele que se encontrava cicatrizada. Notou-se melhora significativa no quadro geral da serpente, que estava alerta e demonstrando apetite normal, além de apresentar capacidade de captura da presa em cativeiro. Por se tratar de animal cativo e que fazia parte da coleção herpetológica do Museu de Zoologia da Universidade Federal de Viçosa, a enucleação não comprometeu os aspectos relacionados à qualidade e ao tipo de vida que a paciente teria após a sua realização. Sabe-se que as serpentes possuem a visão pouco desenvolvida, porém, juntamente com a percepção infravermelha, ela garante a localização exata da presa (LAWTON, 2005). Assim, caso o animal fosse devolvido ao meio ambiente, acredita-se que a enucleação do olho acometido poderia interferir em sua capacidade de sobrevivência.
Por isso, pode-se concluir que a enucleação do bulbo acometido foi um tratamento eficaz, permitindo a plena recuperação da paciente e, ainda, diminuiu o estresse que poderia ter sido causado ao animal por sua manipulação várias vezes ao dia e os riscos de acidentes com a equipe que iria realizar o tratamento.

\section{REFERÊNCIAS}

CARPENTER, J.W. et al. Exotica animal formulary. 2.ed. Philadelphia: Saunders, 2001. 564p.

CULLEN, C.L. et al. Diagnostic ophthalmology. Canadian Veterinary Journal, v.41, p.327-328, 2000. Disponível em: <http://www.ncbi.nlm.nih.gov/pmc/articles/PMC1476148/>. Acesso em: 20 nov. 2012.

GIRLING, S. Basic reptile and amphibian anatomy and physiology. In: __ Veterinary nursing of exotic pets. USA: Blackwell, 2003. Cap.7. p.105-126.

HEARD, D.J.; STETTER, M.D. Répteis, anfíbios e peixes. In: TRANQUILLI, W.J. et al. Lumb \& Jones anestesiologia e analgesia veterinária. São Paulo: Roca, 2013. Cap.35, p.953-974.

HENDRIX, D.V.H. Diseases and surgery of the canine anterior uvea. In: GELATT, K.N. Veterinary ophthalmology. 4.ed. USA: Blackwell, 2007. Cap.17, p.812-858.

HOSER, R.T. On the question of immunity of snake. Litteratura Serpentium, v.5, n.6, p.219-232, 1985. Disponível em: <http:// www.smuggled.com/snaven2.htm>. Acesso em: 10 dez. 2012.

KERN, T.J. Exotic animal ophthalmology. In: GELATT, K.N. (Ed). Veterinary ophthalmology. 4.ed. USA: Blackwell, 2007. Cap.28, p.1370-1405.

LAWTON, M.P.C. Reptilian ophthalmology. In: MADER. (Ed). Reptile medicine and surgery. 2.ed. USA: Elsevier, 2005. Cap.20, p.323-342.

MILLICHAMP, N.J. Exotic animal ophthalmology. In: ANNUAL WALTHAN/OSU SIMPOSIUM SMALL ANIMAL OPHTHALMOLOGY, 25., 2001, USA. Proceedings... Disponível em <http://www.vin.com/OSUWaltham/2001/>. Acesso em: 20 nov. 2012.

WORRELL, E. Reptiles of Australia. 2. Sydney: 1964. 270p. 